\title{
MÚSICA, MEMÓRIA E CULTURA: OS ROMANCES MEDIEVAIS IBÉRICOS NA VOZ DAS RENDEIRAS DE ALCAÇUZ
}

\author{
Ana Judite de Oliveira Medeiros ${ }^{1}$ \\ http://orcid.org/oooo-0oo1-8311-8095 \\ EDUARDO LOPES ${ }^{2}$ \\ http://orcid.org/oooo-00o2-6743-970X
}

\begin{abstract}
Resumo: Numa perspectiva reflexiva para o contexto da cultura e extensão nas universidades, este artigo aborda a inserção dos romances medievais ibéricos encontrados na forma de canção de trabalho reproduzidos na voz e memória de rendeiras no povoado de Alcaçuz, litoral sul do Rio Grande do Norte, Nordeste do Brasil. Tomando como base o conceito de memória coletiva (HALBWACKS, 2008), os romances foram observados a partir do distanciamento da memória histórica local e ampliados na consciência social, quando ressignificados como tema da obra Missa de Alcaçuz. Para a pesquisa, os romances foram identificados, analisados e expostos em cartografia simbólica (SANTOS, 2001), ao qual encontramos afinidades melódicas com a obra Missa e a possibilidade de ampliação do presente, como aproveitamento de diferentes experiências musicais capazes de contribuir para a música contemporânea.
\end{abstract}

Palavras-chave: Romances Medievais; Rendeiras; Memória; Extensão e Cultura.

1 Instituto Federal de Educação, Ciência e Tecnologia do Rio Grande do Norte. (Brasil). Orcid: ooooooo1-8311-8095. Doutoranda em Ciências Sociais pela Universidade Federal do Rio Grande do Norte, e em Doutoramento Sanduiche em Música e Musicologia pela Universidade de Évora. É Mestre em Sociologia da Arte, Especialista em Educação Musical e Professora de Música do Instituto Federal de Educação, Ciência e Tecnologia do Rio Grande do Norte, em que desenvolve atividades de Educação Musical e Canto Coral.

2 Departamento de Música, Universidade de Évora. (Portugal). Orcid: oooo-ooo2-6743-97oX. Doutor em Musicologia pela University of Southampton no Reino Unido. Para além de manter uma atividade significativa como intérprete (bateria e percussão em contexto de música contemporânea e improvisada), a sua pesquisa e publicações enfocam-se nas áreas da Interpretação Musical, Teoria da Música, Ritmo e Métrica Musical, Jazz, e Ensino de Música. É coordenador do CESEM-Centro de Estudos de Sociologia e Estética da Música, pólo da Universidade de Évora, instituição na qual é ao momento Professor Associado com Agregação no Departamento de Música 


\title{
MUSIC, MEMORY, AND CULTURE: THE MEDIEVAL IBERIAN ROMANCES THROUGH THE VOICES OF ALCAÇUZ LACEMAKERS
}

\begin{abstract}
Through a reflective perspective for the context of culture and extension in universities, this article tackles the insertion of the Iberian medieval romances found in the form of a work song reproduced in the voice and memory of lacemakers in the village of Alcaçuz, south coast of Rio Grande do Norte, Northeast of Brazil. Based on the concept of collective memory (HALBWACKS, 2008), the novels were analyzed from the local historical memory and amplified in the social consciousness, as they were re-designated as the theme for the Alcaçuz Mass. For this research, the romances were identified, analyzed and uncovered through symbolic cartography (SANTOS, 2001), for which we found melodic affinities with the Mass and the possibility of amplification of the present, as a use of different musical experiences capable of contributing to the art of contemporary music.
\end{abstract}

Keywords: Medieval Romances; Lacemakers; Memory; Extension and Culture

\section{MÚSICA, MEMORIA Y CULTURA: LOS ROMANCES MEDIEVALES IBÉRICOS A TRAVÉS DE LAS VOCES DE LAS HILANDERAS DE ALCAÇUZ.}

Resumen: En una perspectiva reflexiva para el contexto de cultura y extensión en las universidades, este artículo enfocala inserción delos romances medievales ibéricos encontrados en forma de canción de trabajo reproducidos en la voz y memoria de hilanderas en el pueblo de Alcaçuz, litoral sur de Rio Grande do Norte, Nordeste de Brasil. Tomando como base el concepto de memoria colectiva (HALBWACKS, 2008), las novelas fueron observadas a partir del distanciamiento de la memoria histórica local y ampliadas en la conciencia social, cuando resignificados como tema de la obra Misa de Alcaçuz. Para la investigación, los romances fueron identificados, analizados y expuestos en cartografía simbólica (SANTOS, 2001), en la que encontramos afinidades melódicas con la obra Misa y la posibilidad de ampliación del presente, como formas de aprovechar diferentes experiencias musicales capaces de contribuir con la música contemporánea.

Palabras clave: Romances Medievales; Hilanderas; Memoria; Extensión y Cultura.

Recebido dia 14/01/19

Aprovado dia 21/01/19

\section{INTRODUÇÃO}

Sendo a memória uma das básicas funções e capacidades cognitivas básicas do ser humano, esta tem o poder de armazenar em diferentes medidas, as experiências, acontecimentos e ações que tomamos ou presenciamos. A oralidade e o texto (nos dias de hoje também os media áudio-visuais) não só são formas e ferramentas para a preservação da memória, mas também meios para a criação de memória(s). A preservação de uma memória é indicador da sua relativa 
importância tornando-se assim conhecimento. Do mesmo modo, memória tem parcialmente a capacidade de gerar e preservar culturas. É bem patente a função da memória no processo de culturalização através da transmissão oral de gêneros de poética e música, como por exemplo rimas populares, canções de trabalho e de embalar, Rubin (2009). Torna-se assim claro a importante função da memória na produção e disseminação (expansão) de conhecimento e cultura. Nas sociedades dos dias de hoje uma das instituições onde melhor coabitam conhecimento e cultura é nas Universidades. Segundo Lopes (2015, p. 10):

\footnotetext{
Um pouco por todo o mundo, as instituições universitárias assentam a sua ação em três pilares fundamentais: o ensino; a pesquisa; e a extensão. Sendo genericamente o ensino a função mais associada à universidade, este, nas instituições de ensino superior, estará numa relação muito próxima com a atividade de pesquisa, pois pretende-se que o ensino universitário seja progressista e que acompanhe os novos conhecimentos adquiridos. Desta maneira, a (gênese da) extensão universitária está desde sempre imbuída na universidade, pois toda a produção do seu ensino e pesquisa implica sempre uma futura reação da sociedade, no que respeita à formação dos seus profissionais, bem como à aplicação do conhecimento pesquisado dentro das universidades.
}

Poder-se-á então decorrer que será na extensão universitária, com toda a sua ligação especial e privilegiada à sociedade, que questões de cultura e oralidade encontram um contexto singular para o desenvolvimento de um conhecimento mais inclusivo. Sem negligenciar a relevância da epistemologia positivista, acreditamos também que a procura por outras ontologias que possam abarcar aquilo que por vezes é mais do sentimento do que a razão é também missão da extensão na universidade.

Neste estudo de caso procuramos então dar uma visão musicológica inclusiva de que como a tradição oral dos romances medievais ibéricos encontrados na forma de canções de trabalho, obtiveram visibilidade fora de seu âmbito para a sociedade. Por outro lado, esse foi o material tema que deu vida e título à obra musical Missa de Alcaçuz, uma produção artística da Universidade Federal do Rio Grande do Norte, UFRN. Dessa forma, observa-se que no tocante a extensão, a inclusão de experiências oriundas da cultura popular à sociedade tem sido mediada pela universidade como braço dessa ação. 


\section{OS ROMANCES MEDIEVAIS IBÉRICOS}

Os romances medievais são canções romanceadas que nasceram da poesia provençal, cantados e divulgados por menestréis e trovadores durante a Alta Idade Média, em que preservaram o patrimônio do lirismo ao lado das lendas, superstições e respeito ritualístico ao sobrenatural, desenvolvidos a partir de "jogos florais", fazendo nascer os romances literários, Robertson e Stevens (1977). O mesmo potencial lírico estava na literatura oral das demais gentes da França que na Provença toma a forma de canto e de culto a essa tradição. Há duas expressões que legitimam o estilo provençal: a Félibrige, de onde surge a escola literária e a vocação lírica e os temas de tradição religiosa e mística, santos, milagres, pavores, respeitos, esperanças, no fundamento unificador e defensivo do costume, do hábito, venerado por séculos, que os poetas provençais tomaram esse estilo de vocação lírica e influenciaram a poesia que se tornaria romance na Espanha e Portugal. O segundo estilo é de proximidade castellana e catalã com os seguimentos étnicos locais, fizeram o intercâmbio letrado e popular com a Península Ibérica, determinando essas influências para a América Latina e cristã, criada pela força da Espanha e Portugal, segundo Cascudo (2001, p. 52).

Dois são os aspectos que constituem os romances medievais ibéricos, um textual e outro musical. Sobre o aspecto textual, são divididos em quadras e diálogos seguindo uma mesma métrica para facilitar de compreensão do público tanto da Corte como das cidades; com temática de aventuras, conquistas, fugas e tragédias. Segundo Candé (1995, p. 261):

Os primeiros modelos musicais são versos da escola limusina. Uma canção chama-se, a princípio, verso (Farais un vers, canta Guilherme de Aquitânia). Já em 1096, os cantos destinados a encorajar os primeiros cruzados tiravam suas melodias do repertório dos versos.

Os aspectos textuais incluem a canção, que consiste no texto musicado em que muitas vezes recorria a temas diversos para sua composição. Nesses temas estão presentes variedades como canções romanceadas, na forma de Pastorela, Bergérie, Tensó e Joc, todos seguindo os aspectos textuais dos romances.

$\mathrm{Na}$ ausência de maiores regras formais imperiosas, os temas de inspiração mais frequentes permitiram-se distinguir alguns gêneros habituais à lírica occitânica. Assim, o "Sirventès" (de sirvens = servo da gleba) uma canção política, partidária ou satírica, em que o poeta empenha sua pena na defesa de uma ideia, de um homem ou de uma ação, relacionados com a atualidade. A Cansó 
canta as alegrias e os sofrimentos do amor; literalmente essa palavra significa "canção", mas designa em particular, o grande lirismo provençal em sua forma mais elaborada. De caráter mais narrativo ou dramático, está a Alba ou "canção da alvorada", em que aborda o tema da separação dos amantes, na hora em que a cotovia sucede o rouxinol; costumam ser belas peças em que são evocadas, pela voz do amigo vigilante (os amantes estão demasiado ocupados para cantar), as figuras convencionais do amor cortês. A Pastorela em que põe em cena um cavaleiro que corteja uma pastora (com ou sem sucesso), enquanto a Bergérie canta os amores dos pastores entre si. A Tensó e o Joc Partit (ou Partimen) são curiosos debates dialogados de casuística política (a primeira) ou amorosa (o segundo); correspondendo ao gosto medieval pelos procedimentos judiciários presentes nesses jogos poéticos em que se encontram dois personagens dialogando na mesma melodia diante de uma assembleia ou tribunal. As "cortes de amor procediam sem dúvida desse gênero de diversão (CANDÉ ,1995, p. 266).

Sobre os aspectos musicais dos romances medievais, esses não são tão claros como os textuais. Sem recurso à notação musical, os trovadores memorizavam as melodias dos romances, cantando e tocando intuitivamente de “ouvido". O que se tem conhecimento são registros da tradição instrumental dessa época em que há semelhança com melodias retiradas dos cantos litúrgicos baseados nos modos gregos, mais especificamente àqueles destinados a poesia, a guerra ou ao drama. Durante esse período os modos gregos foram amplamente usados na música cristã dos séculos I a X, em conformidade com a tradição musical judaica dos cantos responsoriais, ou cantos de romagem dos Salmos. Segundo Candé (1995, p. 261):

Ao contrário do que se crê, a inspiração popular só aparece na canção erudita dos trovadores numa época tardia. A influência da melodia pós-gregoriana é largamente, enriquecida pouco a pouco com requintes que talvez sejam tomados emprestados da lírica árabe. A obra dos trovadores nos é conservada em numerosos manuscritos.

$\mathrm{O}$ aspecto musical dos romances teve influência gregoriana na sua melodia, do qual adquiriu características da música litúrgica vocal. Para Robertson e Stevens (1977, p. 71):

Os cantores deviam ter uma memória considerável porque sobreviveram textos grosseiramente escritos. Os trovadores repetiam verso a verso na mesma melodia, num modo de 
balada, como instrumentistas eles improvisavam especialmente los bajos, que se tornou popular na música artística do século XVI.

Esses romances medievais tornaram-se ibéricos a partir da influência da música trazida pelos mouros do norte da África, mais especificamente de uma dança mourisca que se apresentavam com trajes de fantasia. As danças davam o "ponto final" a uma noite de festa, e também era o ato simbólico do ritual do amor cortesão. Não parece assim existir nenhum elemento etnográfico que possibilite o encontro de elementos típicos provençais consensuais integrados aos romances encontrados no Brasil.

\section{ROMANCES MEDIEVAIS IBÉRICOS NO BRASIL}

Os romances medievais ibéricos chegaram ao Brasil por volta de 1500, com a chegada dos portugueses e aqui deixaram raízes na cultura popular. No Nordeste foram encontrados por volta de 1700, como uma forte influência para a música popular de tradição oral. Foram chamados de ibéricos por serem provenientes da Península Ibérica, mas não há nessas melodias elementos diretamente mouros, estes foram deixados nas formas poéticas textuais e melódicas recebidas de Portugal. Segundo Cascudo (2001, p. 11):

\footnotetext{
A expansão moura, Península Ibérica, França, Sicília, as ameaças à Roma papal e o domínio na pirataria do Mediterrâneo, constituem o curriculum ginasial europeu. Portugal de raça latina repassou a mesma convicção lírica de Lisboa fundada por Ulisses. A presença romana foi um enxerto na formação do povo português, que tem fronteira sociológica com a Espanha e África. No século XV, quando Pedro Álvares Cabral rumou ao Brasil, Portugal contaria mais de dois mil anos de participação cultural peninsular.
}

"A partir de estudos etnográficos, apareceram comédias e poemas com notícias outrora privativas de Plauto, Terêncio, Aristófanes, dentre outros gregos e romanos" (SAINTE-BEUVE, 1860 apud CASCUDO, 2001, p. 10), continua: "L’Antiquitité on la dit, est chose nouvelle", a Antiguidade é coisa nova, porque, "Nós somos uma contemporaneidade dos milênios". Segundo o autor, mouros e judeus não foram deparados nos livros, mas na vivência de usos e costumes brasileiros, podendo observá-los no Sertão do Rio Grande do Norte,

[...] É bem notado no tabu do sangue, repugnância às carnes dos animais encontrados mortos, balançar o corpo na oração, a bênção com a mão na cabeça, o horror da blasfêmia, 
respeito ao cadáver e aos objetos de uso pessoal do morto, pavor aos mistérios da noite de lua nova, das estrelas cadentes, do relâmpago, do trovão, a voz do Deus irado, às perfídias do anjo mal, dentre outras crenças. Continua, a autenticidade da presença do Oriente no Nordeste, como o temor das sombras, das águas paradas, o torvelinho de folhas secas, aleijados de nascença, velhos de barba longa e homem de fala fina (CASCUDO, 2001, p. 13).

Em suas palavras esse era um orientalismo "diluído no leite materno das amas-pretas, acalentadoras das impaciências infantis" (p.15).

A cultura da Provença veio a influenciar o Brasil, sobretudo o Nordeste, não diretamente, mas através da influência galaico-portuguesa. O que já estava quase esquecido na Europa da Península Ibérica, ganhavam vida no Brasil, incluindo a América Espanhola, como Mireio, centro de interesse tradicional, o poema-síntese da terra e da gente do $\mathrm{Crau}^{1}$. O Nordeste do Brasil foi a região que mais absorveu dessa cultura presente em muitos episódios que envolviam o Imperador Carlos Magno, transformados em dramas cantados e recitados em sextilhas e décimas, como no romance ibérico "Dona Branca”, encontrado no Romanceiro de Alcaçuz (GURGEL, 1992).

Aquando da chegada dos portugueses ao Brasil, já não havia presença moura em Portugal há 259 anos. Na Espanha, no final do século XV quando Granada tornou-se castellana, Cristóvão Colombo saiu para sua jornada pelo mundo. O mouro viajou para o Brasil na memória de quem ali chegou e aqui ficou até os dias de hoje; sua presença é marcante na cultura popular do Nordeste litorâneo e sertanejo. Suas marcas encontram-se nas canções de ninar de lembrança moura:

Bão-babalão, senhor capitão, espada na cinta e ginete na mão...

Bão-babalão, senhor capitão, em terras de mouro morreu seu irmão (...).

No Brasil repetiram-se essas canções romanceadas numa tradição moura sobre as mulheres. Era recomendado para as mulheres a reclusão na Península Ibérica, o ciumento recato que afastava as damas e donzelas do contato social masculino, teria fontes no domínio mouro, reminiscências do harém. Por todo o século XIX essa era a tradição no interior do Brasil, sobretudo no sertão nordestino "profundo": distanciar a mulher do homem, apenas pelo aparentado do pai, do irmão, padrinho ou marido. Semelhantemente por toda América Espanhola são registrados o isolamento em que vivia a família, mesmo abastada, e as raras ocasiões em que o visitante era generosamente 
recebido, percebia o vulto de mulher, rápido e sempre fugitivo aos olhos dos estranhos Gurgel (1992) e Cascudo (2001). Essa era uma fórmula medieval de etiqueta soberana (CASCUDO, 2001, p. 24), expressa nas canções romanceadas, uma herança moura diluída na cultura portuguesa e que chegou até o Brasil, criando raízes no gosto popular da tradição oral.

Os romances medievais ibéricos existiram com outras denominações em diferentes países europeus, mas em Portugal e Espanha ganharam maior projeção, e no Brasil ao chegarem, foram espalhados principalmente por toda a costa do Nordeste, Gurgel (2006, p. 67). Dada a situação geográfica, o Rio Grande do Norte foi o lugar mais visitado, sendo o município de Ceará Mirim o registro mais próximo dos romances ibéricos trazidos por portugueses e espanhóis.

\section{AS RENDEIRAS DE ALCAÇUZ}

Em Alcaçuz, distrito do município de Nísia Floresta, no Rio Grande do Norte, foram recolhidos na voz de rendeiras os romances medievais ibéricos utilizados nas melodias da obra musical Missa de Alcaçuz, composta por Danilo Guanaes em 1996, que lhes deram vida e título.

Alcaçuz está situada entre dunas e lagoas, ao sul do Estado do Rio Grande do Norte próximo à praia de Pirangi do Sul, trinta quilômetros de Natal. Historicamente, o nome de Alcaçuz remonta a mais antiga tradição da região onde está localizado o povoado. As praias de Búzios e Pirangi, a três quilômetros ao nordeste da povoação, figuram nas primeiras cartas geográficas do litoral potiguar.

Segundo o historiador Antônio Soares (1985), "Pirangi possuía, em 1614, dois portos de pescaria, um em que sempre se pescou que é o da banda do sul, e o da banda do norte haverá dez anos que o deixou João Sereminho" (SOARES, 1985, p. 94). A mais antiga referência histórica encontrada sobre o nome do povoado está num formal de partilha, em poder de João de Vitôr (sic), dono do bar do cajueiro, em Pirangi do Norte, no qual se menciona o nome de Alcaçuz, no ano de 1711, segundo Gurgel (1992).

Alcaçuz está numa depressão do terreno a caminho de Pirangi à Nísia Floresta, via Cachoeira, entre morros cobertos de vegetação e lagoas de águas mansas. As lagoas que a cercam são de grande importância para a sobrevivência de seus moradores ${ }^{2}$. Dos morros que circundam a povoação, os principais são o Morro do Pinica-Pau, o Morro do Arrepio e o Morro do Navio, de grande importância na orientação dos pescadores em alto mar no seu regresso à terra 
(GURGEL, 1992, p. 16). A maioria dos habitantes de Alcaçuz são pescadores, caçadores e agricultores que se dedicam-se ao plantio de mandioca, para a produção de farinha. As mulheres de Alcaçuz, em sua maioria, são rendeiras em que através das músicas na canção de trabalho, foram observadas e recolhidos pelo folclorista Deífilo Gurgel, que comenta: "são penélopes caboclas que passam o dia diante da almofada, nos intervalos roubados aos afazeres domésticos, tecendo rendas, para ajudar na renda familiar" (GURGEL, 1992, p.17).

É antiga a arte de fazer rendas cantando romances em Alcaçuz. Em pesquisa anterior a 1973, realizada no litoral dos estados do Rio Grande do Norte, Ceará e Paraíba, Osvaldo de Souza (1973) refere-se com frequência à arte das rendeiras de Alcaçuz: "Em Alcaçuz, lugarejo situado à margem da lagoa de igual nome, no município de Nísia Floresta (Rio Grande do Norte), as rendeiras costumam trabalhar em conjunto: é fácil encontrá-las em grupo de dez ou mais, nos terreiros à sombra de alguma árvore" (SOUZA, 1973, p. 7).

"Em Alcaçuz foram encontrados os romances medievais ibéricos em canções versificadas e poemas musicados, neles são descritas ocasiões palacianas, histórias galantes de amores e intrigas da nobreza, permeadas de aventuras de cavalaria e tragédias" (GURGEL, 1992, p. 11). Segundo o autor esses romances estão em forma de canções de trabalho por mulheres rendeiras locais, como antes havia constatado sua presença, que caíram nas raízes do gosto popular. No relato das rendeiras os cantos são transmitidos de mãe para filha através da tradição oral, sem qualquer registro de notação musical, mas guardado em sua memória individual e depois na memória coletiva durante seu ofício de "rendar na almofada".

Os romances cantados e relembrados pelas rendeiras durante sua arte, são elementos vivos das canções romanceadas e da tradição de literatura oral, como parte de suas lembranças de caráter afetivo, de contos da infância, sendo mantidos vivos na coletividade. É na memória coletiva que esses romances são trazidos e alimentados pela memória individual de cada rendeira, contribuindo para manter presentes e vivos a cultura popular.

Ao tratar de memória coletiva como importante ferramenta nesse processo, recorremos a abordagem de Halbwachs (2008) quando considera que o depoimento da testemunha é relevante e significativo no grupo, quando pressupõe um evento real vivido, no caso das rendeiras/romanceiras, os romances cantados em canções de trabalho. Para o autor é através de um evento, do 
contexto vivido de referência que o grupo guarda sua memória coletiva, reconstruindo a lembrança e mantendo viva.

\begin{abstract}
A memória individual existe, mas está enraizada em diferentes contextos que a simultaneidade ou a contingência aproxima por um instante. A recomendação pessoal está situada na encruzilhada das redes de solidariedade múltiplas em que estamos envolvidos. Nada escapa à trama sincrônica da existência social atual, é da combinação desses diversos elementos que pode emergir aquela forma que chamamos lembrança, porque a traduzimos em uma linguagem. (2008, p.12).
\end{abstract}

Foram as lembranças musicais das rendeiras/romanceiras que mantiveram viva a tradição de cantar os romances ibéricos enquanto "rendavam" em suas almofadas na sombra dos cajueiros em Alcaçuz. Segundo Gurgel (1992), é possível perceber nos romances as seguintes características ibéricas: o texto dividido em quadras e diálogos seguindo uma mesma métrica; sua temática de aventuras galantes, conquistas, fugas e tragédias; e a melodia baseada nos modos litúrgicos comumente usados durante a Idade Média. Ele comenta, "Ao ouvir 'Paulina e Dom João', reconheci todas as características de um romance tradicional ibérico, mas inteiramente inédito, nas coletâneas dos diversos pesquisadores brasileiros" (GURGEL, 1992, p. 25). Durante a visita à Alcaçuz em agosto de 1985, o autor interessou-se em conversas com habitantes locais sobre sua cultura, sobretudo sua música e lembrou-se da pesquisa para o Romanceiro Potiguar que já havia começado, foi quando arriscou perguntas sobre os antigos romances medievais que sabia de sua existência naquela região. Em conversa com Dona Isabel, moradora de Alcaçuz, ela lhe relatou que cantava quatro romances e ainda indicou Dona Maria de "Seu" Aleixo, que sabia de mais sete, todos cantados enquanto faziam suas rendas. Essas descobertas fizeram que Gurgel retornasse por várias vezes à Alcaçuz para entrevistar e gravar os romances. Em toda sua pesquisa de campo encontrou um dos mais importantes romances coletados com o título "Paulina e Dom João", este, com todas as características de um romance tradicional ibérico, mas inteiramente inédito, nas coletâneas dos diversos pesquisadores de campo, (GURGEL, 1992, p. 25). Considerados por sua importância histórica e estilística, esses romances foram incluídos na obra Missa de Alcaçuz, dando-lhes título e vida à obra.

São as rendeiras que dão voz a pesquisa, é o seu canto que guarda a memória individual dos contos e romances alimentados pela memória coletiva reconhecidos como consciência social. É a memória coletiva que não se confunde com 
a história, porque se fosse apenas com base na história individual de cada uma, isso resultaria numa construção cristalizada por um grupo estabelecido, um período, uma data, mas, enquanto memória coletiva tem na sua construção o acréscimo de várias memórias individuais, e dessa forma consegue defender-se da "erosão" permanente das mudanças do tempo. Para Halbwachs (2008, p. 72):

\begin{abstract}
A memória coletiva contém as memórias individuais, mas não se confunde com elas evolui segundo suas leis e, se às vezes determinadas lembranças individuais também invadem, dessas mudam de aparência a partir do momento em que são substituídas em um conjunto que não é mais uma consciência pessoal.
\end{abstract}

Ao relacionar o conceito de memória coletiva trazido pelo autor aos romances ibéricos, pode-se perceber que esses, mesmos quando aprendidos individualmente, são reforçados em grupo sendo essa a maneira que adquirem a força da memória coletiva e renovam-se como outros romances cantados em canções de trabalho. Para Halbwachs (2008), a diferença acentuada entre a memória coletiva da memória histórica, está na sua eficácia em construir a memória de um grupo e para chegar a tal conclusão, o autor esclarece a partir de uma perspectiva sociológica em que descreve e analisa as ações sociais concreta a partir de suas próprias condições seja de linguagem, de ordem, de instituições ou de tradição. Segundo ele não é possível pensar em nós mesmos, senão pelos outros e para os outros, sob a condição do coletivo para se obter o universal.

A "memória coletiva" não deve nada à "memória histórica" e tudo à "memória coletiva”, é porque a primeira está localizada na interseção de muitas séries aproximadas pelo acaso ou pelo nivelamento dos grupos - a memória não poderia ser o alicerce da consciência, pois é apenas uma de suas direções, uma perspectiva possível que o espírito racionaliza. (2008, p.14).

É através da memória coletiva que são percebidos os acontecimentos humanos mais simples, tal como ocorrem na vida real durante as inúmeras dramatizações em que se enfrentam os papeis reais e imaginários, as projeções utópicas e as construções arbitrárias. Halbwachs, sob influência de Durkheim (1893), sempre buscou combinar o método objetivo do cientista e o método reflexivo do filósofo, foi um observador fiel da vida social concreta e cotidiana destacando a nobreza, a propriedade, a relação entre gerações, a função dos mais velhos como guardiões do passado e o papel dos nomes na linguagem e nas relações humanas. As relações com a memória e a sociedade tornou-se para ele o centro 
do seu pensamento, sendo esta a razão da escolha teórica quanto a transmissão oral dos romances ibéricos assegurada pela memória coletiva.

Percebemos que é na tradição ibérica dos romances cantados pelas rendeiras de Alcaçuz, que está presente a memória coletiva como sua herança musical. Foi o recurso da memória que tornou o instrumento decisivo, na voz dessas mulheres. É a experiência de vida das pessoas, seu cotidiano que pode ser utilizado como matéria-prima, dando uma nova dimensão à história observada através dela (THOMPSON, 1992). A experiência musical das rendeiras, representada em cada romance que a memória coletiva de um grupo foi estabelecida. Em primeiro lugar essa memória esteve numa condição individual e histórica, e em segundo, coletiva sendo "alimentada" por outras rendeiras/romanceiras em canções de trabalho.

Nesses processos a memória é um excelente recurso na capacidade de adquirir, armazenar e recuperar informações disponíveis, porque focaliza coisas específicas e conecta pedaços da história e conhecimentos a fim de gerar novas ideias, ajudando a tomar decisões diárias (TOMAZ, 1992). Há duas definições distintas para a memória na neurociência, a memória declarativa e a não declarativa, que a grosso modo, a declarativa, armazena o saber de algo que se deu, e a memória não-declarativa em como isto se deu. A memória declarativa, ou memória de longo prazo como o nome sugere, é aquela que pode ser declarada com fatos, nomes, acontecimentos, e é mais facilmente adquirida, mas também, é mais rapidamente esquecida (1992, p. 193).

$\mathrm{Na}$ audição dos romances o que detectamos haver é a memória declarativa presente no canto das rendeiras/romanceiras, também identificadas como memória episódica, que revela as lembranças de acontecimentos específicos; e a memória semântica, que revela as lembranças de aspectos gerais ${ }^{3}$. Para Bergson (2006), Levi (1999) e Thompson (1992), a memória tem se consagrado a base de conhecimentos diversos e como tal, deve ser trabalhada e estimulada, sendo através dela que o cotidiano adquire significado e acumula-se experiências para utilizar durante a vida.

Na reconstrução de um passado "inteligente", em que se guarda e transmite os acontecimentos, a memória é uma espécie de regente de todo o processo nas relações com a matéria sonora. Desse processo permanece ativos o passado e o presente, circunscrevendo os limites de interpretação, tem-se a imagem ou som/ com um tipo de lembrança possível de identificar a relação com os demais objetos ou sons, onde, ao invés de experimentar as imagens, essas são 
trazidas tentando recuperar sua claridade, e, principalmente, sua utilidade em nossas vidas. São das imagens-lembrança que nasce o reconhecimento dos objetos: sua comunicabilidade e o reconhecimento "inteligente", ou melhor, intelectual, de uma percepção já experimentada, segundo Bergson (2006). É necessário um tutti de memória na construção da memória coletiva.

Foram as experiências, a troca de "receitas" de rendas e de romances cantados, que mantiveram as rendeiras/romanceiras como personagens vivos na transmissão dos romances medievais ibéricos que tomaram parte ressignificados na obra Missa de Alcaçuz. No uso de sua memória musical na transmissão dos romances, tornou-se possível o conhecimento desse gênero musical, tomados a partir da pesquisa de Deífilo Gurgel desde 1985, com entrevistadas a essas mulheres que contavam suas histórias e cantavam os romances, tendo seus relatos transcritos em textos e sistematizados em solfas reunidos no Romanceiro de Alcaçuz (GURGEL, 1992).

Com base no conceito de memória coletiva, foram examinados esses romances medievais a partir da audição das rendeiras em suas canções de trabalho, de como guardam as lembranças da infância e juventude, acrescentadas de novos episódios e histórias palacianas, que por vezes confundem-se com as suas próprias, mantendo viva a tradição dos romances na cultura popular. Essa experiência foi observada durante a coleta de dados, ao ouvir a rendeira Dona Dudu, enquanto cantava os romances "Delgadinha", "Antonino" e o baião "Mulher Rendeira”, em janeiro de 2013. Num primeiro momento a rendeira fez um breve relato de sua vida, de como aprendeu os romances em casa, com a mãe e as tias, enquanto fazia renda na almofada com bilros, e depois em companhia de outras rendeiras em Alcaçuz. Durante a audição com a rendeira Dona Dudu foi possível identificar as seguintes características medievais ibéricas: o texto dividido em quadras com rimas, de melodia em tonalidade modal e temática medieval contando aventuras galantes, fugas, conquistas e tragédias. Eis o relato do romance "Delgadinha".

A estória da "Delgadinha" ou "Faustinina", é assim: A moça rejeitando as propostas de amor "errado" do rei, seu pai, é presa na torre mais alta do castelo, sem água e sem comida. De lá avista a mãe, os irmãos, o secretário do palácio, e lhes roga, pelo amor de Deus, uma gotinha d'água, que a menina chama de "jolvinho d'água". Todos se negam ajudar a moça, temendo a vingança do rei. Desesperada de sede, ela concorda ser a "namorada" de seu pai, Em troca de um jarro d'água. Quando os criados entram em sua cela, a Delgadinha já está morta e uma legião de anjos vai levando a sua alma para o céu. No mesmo instante, 
o pai que queria o amor "errado" e levado por um bando de demônios que o arrebatam para o inferno $(s i c)^{4}$.

Segue o romance ibérico "Delgadinha" em alguns de seus versos.

Delgadinha era bonita que bonita não havia,

Pela boniteza dela que o pai dela perseguia

- 'Delgadinha se tu qués ser minha namorada

De ouro andais vestida, de prata andarás calçada'.

- 'Ô, meu pai, deixe-se disso dessa sua tentação,

Encoste-se à sua igreja e vá ouvir de contrição.

Eu não quero o seu ouro nem também a sua prata.

Quero ser sua filha, muito bela e estimada'.

- 'Delgadinha tu não queres ser a minha namorada,

Mando butar na montanha, não te deixo dar-te água'.

- 'Me vala, nossa Senhora, e o meu Bom Jesus dos Passos,

Me tire dessas montanhas, me bote em torre mais alta. (...) ${ }^{5}$.

É possível observar muitas estrofes com repetição a cada dos versos em quadra e a temática medieval com a descrição de elementos textuais como: a casa é o palácio, o quarto da Delgadinha é uma cela, o castigo na torre mais alta, o irmão jogando sua espada, a mãe regendo sua casa, o pai é o rei e ele está jogando com seu "sacrataro" (sic), secretário, e esses romances eram cantados, contado tragédias em meio a contexto diferente do seu cotidiano. São essas melodias que irão compor o tema da Missa de Alcaçuz, numa aproximação entre a cultura popular e erudita na mesma obra sem que ambas percam suas características.

\section{OS ROMANGES NA MISSA DE ALGAÇUZ}

A Missa de Alcaçuz, uma obra para solistas, coro e orquestra foi composta por por ocasião das atividades da Semana da Música na Universidade Federal do Rio Grande do Norte, utilizou dos ritmos e melodias da cultura popular de tradição oral, principalmente dos temas dos romances que lhe deu o título. Nos cantos da Missa, que seguem a liturgia católica encontram-se trechos dos romances em afinidades melódicas porque e ambos pertencerem à mesma origem musical: os modos gregos. Para a constatação foram identificados, analisados e expostos em quadro de comparações, em cartografia simbólica autoexplicativa (SANTOS, 2000). 
No processo de identificação das afinidades melódicas foram elaborados três cartogramas a fim de localizar e atribuir resultados dessa aproximação sob os seguintes referenciais metodológicos: projeção, escala e simbolização. Com tal procedimento encontramos não apenas afinidades, mas possiblidades de ampliação do presente, como razão metonímia, com o aproveitamento de diferentes experiências musicais capazes de contribuir para a música contemporânea. A utilização da metáfora do mapa para o cartograma permite-nos enxergar uma realidade específica a partir de uma representação visual ou imaginária, já que todo mapa traz consigo um ideário que o formula tal como se apresenta, em que a imagem e o valor da representação se fundem. Neste sentido, construir um mapa para visualizar a obra Missa de Alcaçuz, sobretudo, as tensões que ligam a música popular a música erudita, é um exercício metodológico importante para explicitar a inserção e envolvimento das melodias dos romances ibéricos na obra.

Portanto, para identificar os romances na obra Missa, o caminho que nos permitiu maior clareza foi a exposição panorâmica da obra em cartografia simbólica, que, segundo Santos (2000), a cartografia simbólica é uma estratégia metodológica em que envolve a construção de quadros interpretativos que acomodam mapas igualmente interpretativos da realidade que se quer representar. $\mathrm{Na}$ cartografia da obra musical encontramos a influência dos romances cantados pelas rendeiras na construção melódica da obra Missa de Alcaçuz, possibilitando identificá-los na preservação da tradição ibérica no Rio Grande do Norte. Esses romances que nos pareciam "invisíveis" ou ausentes no contexto da música potiguar, tornaram-se visíveis e presentes na música contemporânea.

Para a exposição dos romances em cartografia simbólica, foram destacadas quatro partes da Missa de Alcaçuz, onde acomodam as seguintes melodias dos romances: Quoniam, Qui Propter, Et Spiritum Sanctum e Agnus Dei, nessas partes estão os romances, respectivamente: "Juliana e Dom Jorge", "Dona Branca", "Santa Iria", “Antonino", "Paulina e D. João" e "O Conde Aragão". A escolha dessas partes deve-se a dois fatores: o primeiro, por uma questão operacional a fim de visualizar a obra como um todo; e segundo, porque as partes selecionadas apresentam a contento a discussão que desejamos explicitar. Os cartogramas são autoexplicativos, assim como os mapas. Sua leitura permite a interpretação sem maiores esforços de acordo com a subjetividade e compreensão de cada leitor. O procedimento evidenciou a centralidade da 
racionalidade e do processo de fusão ocorrido na obra enquanto operador cognitivo de mediação entre as partes do cânone e as melodias dos romances.

CARtocrama de Apresentação panorâmica da obra Missa de Alcaçuz

\begin{tabular}{|c|c|c|c|c|}
\hline MISSA & ROMANCES & LOCALIZAÇÃo & RITMOS & ESTILOS MUSICAIS \\
\hline KYRIE & - & - & BAIÃO & ARMORIAL \\
\hline GLORIA & -- & - & MARACATU & ARMORIAL \\
\hline LAUDAMUS & - & -- & - & TONAL \\
\hline GRATIAS AGIMUS TIBI & - & - & XAXADO & TONAL \\
\hline Domine Deus & - & -- & - & HaRM. CLÁSSICA \\
\hline QUI TOLLIS & - & - & -- & HARM. CLÁSSICA \\
\hline QUONIAM & JULIANA E D. JORGE & $\begin{array}{l}\text { C. } 31-41 \text {, } \\
\text { VIOLONCELO }\end{array}$ & ABOIO/XAXADO & HARM. CLÁSSICA \\
\hline CUM SANCTO SPIRITUM & - & - & VÁRIOS RITMOS & Polifonia \\
\hline CREDo & - & - & XAXADO & DISCANTO \\
\hline Deum de Deo & - & - & - & HARM. CLÁSSICA \\
\hline QUI PROPTER & $\begin{array}{l}\text { D. BRANCA/ STA. } \\
\text { IRIA/ANTONINO }\end{array}$ & $\begin{array}{l}\text { C.9-24, } 1^{\circ} \text { VIOLINO } \\
\text { C. } 9-24, \quad 2^{\circ} \text { VIO- } \\
\text { LINO C. } 24,45,2^{\circ} \\
\text { VIOLINO }\end{array}$ & ACALANTO & MODAL \\
\hline ET INCARNTUS & - & - & CABOCOLINHOS & POLIFONIA BARROCA \\
\hline CRUXIFICUS & - & - & - & POLIFONIA BARROCA \\
\hline ET RESURREXIT & - & - & -- & HaRM. CLÁsSICA \\
\hline ET IN SPIRITUM SANCtUM & Paulina E D. JoÃo & $\begin{array}{ll}\text { C. } 46-54, & 1^{\circ} \\
\text { VIOLINO } & \end{array}$ & VÁRIOS RITMOS & POLIFONIA \\
\hline CONFITEOR & - & - & -- & CANTOS MEDIEVAIS \\
\hline ET VITAM VENTURI & - & - & - & POLIFONIA \\
\hline SANCTUS & - & - & - & CANÇÃo \\
\hline HOSANNA & - & - & -- & POLIFONIA BARROCA \\
\hline BENEDICTUS & - & - & - & BARROCO \\
\hline HOSANNA & - & - & -- & POLIFONIA BARROCA \\
\hline AGNus DeI & $\begin{array}{l}\text { O CONDE ARACÃo/ } \\
\text { STA. IRIA }\end{array}$ & $\begin{array}{l}\text { C.72-77;136-141 } 1^{\circ} \mathrm{E} \\
2^{\circ} \text { VIOLINO C. } 72- \\
\text { 144;136-144, VIOLA }\end{array}$ & BAIÃO & HARM. CLÁSSICA \\
\hline
\end{tabular}

FONTE: MEDEIROS (2014).

Os temas dos romances medievais ibéricos aparecem nos trechos identificados nos compassos e linha melódica de cada instrumento musical descriminado acima. Ao ouvir os romances e os trechos da Missa de Alcaçuz é possível 
identificá-los como também, que na percepção da obra como um todo, que é estabelecida a partir das melodias desses romances. É perfeitamente identificável como, através de ritmos e estilos de raiz popular e/ou regionalizados, a cultura popular transborda para a erudita, e paralelamente esta última ressignifica todo o produto artístico através da memória, resultando num todo que é funcional e ao mesmo tempo gerador de diferentes experiências artístico-musicais.

\section{CONCLUSÃO}

Ao final dessa pesquisa percebemos que a música apesar de sua lógica interna, como um produto de uma cultura, ou de culturas que se fundem, é capaz de visualizar práticas invisíveis e ausentes sem desperdiçar experiências úteis para a música contemporânea. A pesquisa permitiu-nos compreender que a música não revela apenas uma dinâmica social, mas a dinâmica do próprio indivíduo enquanto agente social, quando imprime numa obra musical seus valores e práticas que poderiam estar invisíveis. $\mathrm{Na}$ aproximação com as rendeiras de Alcaçuz e seus romances, foi possível perceber o interesse em manter viva essa cultura feminina de cantar romances em canções de trabalho, quase extinta nos dias atuais, e que práticas como essas devem ser visualizadas e presentes na sociedade, por sua contribuição à música popular de tradição oral no Rio Grande do Norte. A relevância por nós encontrada nesse tema, dá-se pela importância de compartilhar esse conhecimento a fim de ampliar o presente aproveitando as diferentes experiências musicais. E, portanto, essa compreensão de tempo e a compreensão do indivíduo, ou indivíduos, como unidade final é o que entendemos e buscamos na sua utilidade e aplicação na obra estudada. Concluímos que os romances medievais ibéricos alimentados pela memória coletiva das rendeiras de Alcaçuz contribuíram para construção melódica e visualização da música antiga no Rio Grande do Norte, como patrimônio da música potiguar.

Nesse processo tem-se a memória que gera cultura e conhecimento, e esse podendo ser ressignificado de diferentes formas. Os resultados obtidos com a pesquisa entre os romances medievais ibéricos e a obra Missa de Alcaçuz, observa-se como é possível o trânsito bilateral entre a cultura popular de tradição oral e a cultura erudita, sem que ambas percam sua essência e estrutura. Ao trazer a tradição oral à tona ressignificada em obra erudita, e esta, visível 
na sociedade, fora de seu âmbito original, tem-se mediação da extensão universitária na aproximação de comunidades distantes dos poderes centrais com a sociedade, como também na dupla ação, em que de um lado está sua visibilidade, e de outro lado, também vai buscar/colher/aprender e refazer-se com ela. Foram os romances medievais ibéricos, transmitidos através da memória e da voz de mulheres rendeiras em suas canções de trabalho, na localidade de Alcaçuz, que se tornaram ressignificados na obra Missa de Alcaçuz, dando-lhe vida e título, como parte do movimento de uma sociedade orgânica em que as diferentes experiências musicais são aproveitadas.

Três aspectos destacam-se neste estudo de caso, o primeiro que diferentes estilos musicais podem nascer da mesma raiz, comprovado em suas aproximações melódicas; o segundo aspecto, que as experiências musicais não sejam desperdiçadas; e o terceiro, de como a extensão universitária pode promover o ensino e a pesquisa no momento em que transita de forma bilateral, que leva o conhecimento à sociedade, como tem nela a sua fonte.

\section{REFERÊNCIAS}

BERGSON, H. Matéria e Memória: ensaio sobre a relação do corpo com o espírito. 3.ed. São Paulo: Martins Fontes, 2006. (Coleção Tópicos).

CANDÉ, Roland. História Universal da Música. São Paulo, Martins Fontes, 1995. v.1. CASCUDO, Câmara. Contos Tradicionais do Brasil. Rio de Janeiro: Ed. Ouro, 1978. . Literatura Oral. Rio de Janeiro: Livraria José Olympio, 1952. . Mouros, Franceses e Judeus: três presenças no Brasil. São Paulo:

Global, 2001. As culturas populares no capitalismo. São Paulo: Brasiliense, 1983.

GURGEL, Deífilo. Espaço e Tempo do Folclore Potiguar. 2. ed. Natal: Governo do Estado do Rio Grande do Norte, 2006. (Coleção Folclore Potiguar).

Romanceiro de Alcaçuz. Natal: UFRN/PROEX/Cooperativa Cultural. Ed. Universitária, 1992.

HALBWACHS, Maurice. A Memória Coletiva. 3. ed. Tradução de Beatriz Sidou. São Paulo: Centauro Editora, 2008.

LEVI, Giovanni. Usos da Biografia. In: AMADO, Janaína; FERREIRA, Marieta de Moraes. Usos \& Abusos da História Oral. Rio de Janeiro: da Fundação Getúlio Vargas, 1999. p.304-310. 
LOPES, Eduardo. O Ritmo e a Improvisação musical como veículo para a Extensão Universitária. Revista da Universidade Federal de Goiás, Ano XV Nr. 16, junho 2015, pp. 8-22. LYRA, Tavares. História do Rio Grande do Norte. 3. ed. Natal: EDUFRN, 2008.

MEDEIROS, Ana Judite. Missa de Alcaçuz: aproximações melódicas com os romances medievais ibéricos. 2014. Mestrado (Dissertação). Programa de Pós-Graduação em Ciências Sociais, Universidade Federal do Rio Grande do Norte.

ROBERTSON y STEVENS (Org.). História General de la Música: desde la Renacimiento al Barroco. Madrid: Ediciones Istmo, 1977. (Col. Fundamentos, v.6).

RUBIN, David. Oral Traditions as Collective Memories: Implications for a general theory individual and collective memory. In: BOYER, Pascal; WERTSCH, James. Memory in Mind and Culture. Cambridge University Press, pp. 273-287, 2009.

SANTOS, Boaventura de Sousa. Uma Cartografia Simbólica das representações sociais: o caso do direito. In: . A crítica da razão indolente: contra o desperdício da experiência. São Paulo: Cortez, 2000. p. 63-80.

SOARES, Antônio. Notas da História, obra póstuma. Natal: Fundação José Augusto, 1985. Apêndice com a notações ao texto, de Antônio Soares Filho.

SOUZA, Laura de Mello. A cultura popular e a história, em Seminário folclore e cultura popular: as várias faces de um debate. 2. ed. Rio de Janeiro: Funarte, 2000.

SOUZA, Osvaldo. Rendas e Labirintos do Nordeste. Natal: Fund. José Augusto, 1973.

THOMPSON, Paul. A Voz do Passado: história oral. Rio de Janeiro: Paz e Terra, 1992.

TOMAZ, C. Memória e Emoções. Ciência Hoje, n.83, p.25-30, agosto 1992. 